\title{
The effect of probiotics on quality of life in women with primary dysmenorrhoea: a randomized, double-blind, placebo-controlled trial
}

Izyan Atiqah Zakaria ${ }^{1}$, Kah Teik Chew ${ }^{1}$, Muhammad Azrai Abu ${ }^{1}$, Ani Amelia Zainuddin ${ }^{1}$, Nor Haslinda Abdul Aziz ${ }^{1}$, Nazarudin Safian ${ }^{1}$, Norfilza Mohd Mokhtar ${ }^{1}$, Raja Affendi Raja Ali $^{1}$, and Nur Azurah Abdul Ghani ${ }^{1}$

${ }^{1}$ National University of Malaysia Faculty of Medicine

October 16, 2020

\begin{abstract}
Objective: To investigate the effects of 3-month supplementation with oral probiotics on quality of life in young women with primary dysmenorrhoea Design Randomized, double blind, placebo-controlled trial Setting A tertiary university hospital in Malaysia Population Women aged 18 to 45 years old suffering from primary dysmenorrhoea Methods: 72 patients were randomized to receive either oral sachets containing Lactobacillus acidophilus, Lactobacillus casei, Lactobacillus lactis, Bifidobacterium bifidum, Bifidobacterium longum, and Bifidobacterium infantis $107 \mathrm{mg}$ each or placebo twice daily for three months. Main outcome measures Visual Analog Score (VAS) of pain, Verbal Rating Scale (VRS) of severity, frequency of non-steroidal antiinflammatory drugs (NSAIDs) use, and quality of life (QoL) scores derived from Short Form 12 item version 2 (SF12v2) questionnaire Results Both groups showed improvement in quality of life scores. There was a non-statistically significant lower NSAIDs use in probiotic group compared to placebo group (median 1 vs 2 , p-value $=0.26$ ). Placebo group showed better severity score (VRS) on day 2 of menses compared to probiotic group (median 0 vs 1 , p-value $<0.05$ ). No difference in other quality of life scores was noted. In subgroup of non-NSAIDs users, the pain score (VAS) was lower in the probiotic group compared to placebo, which was not statistically significant ( $\mathrm{p}$-value $=0.59$ ) Conclusion Probiotic supplement may reduce NSAIDs use in women with primary dysmenorrhoea Funding This study receives supply of the oral probiotic sachets and placebo from the manufacturing company Hexbio Sdn Bhd Keywords Primary dysmenorrhea, probiotics, quality of life, menstrual disorders
\end{abstract}

\section{Design}

Randomized, double blind, placebo-controlled trial

\section{Setting}

A tertiary university hospital in Malaysia

\section{Population}

Women aged 18 to 45 years old suffering from primary dysmenorrhoea

Method s:

72 patients were randomized to receive either oral sachets containing Lactobacillus acidophilus, Lactobacillus casei, Lactobacillus lactis, Bifidobacterium bifidum, Bifidobacterium longum, and Bifidobacterium infantis $107 \mathrm{mg}$ each or placebo twice daily for three months.

\section{Main outcome measures}


Visual Analog Score (VAS) of pain, Verbal Rating Scale (VRS) of severity, frequency of non-steroidal antiinflammatory drugs (NSAIDs) use, and quality of life (QoL) scores derived from Short Form 12 item version 2 (SF12v2) questionnaire

\section{Results}

Both groups showed improvement in quality of life scores. There was a non-statistically significant lower NSAIDs use in probiotic group compared to placebo group (median 1 vs 2 , p-value $=0.26$ ). Placebo group showed better severity score (VRS) on day 2 of menses compared to probiotic group (median 0 vs 1 , p-value $<0.05$ ). No difference in other quality of life scores was noted. In subgroup of non-NSAIDs users, the pain score (VAS) was lower in the probiotic group compared to placebo, which was not statistically significant $(\mathrm{p}$-value $=0.59)$

\section{Conclusion}

Probiotic supplement may reduce NSAIDs use in women with primary dysmenorrhoea

\section{Funding}

This study receives supply of the oral probiotic sachets and placebo from the manufacturing company Hexbio Sdn Bhd

\section{Keywords}

Primary dysmenorrhea, probiotics, quality of life, menstrual disorders

Trial registry: ClinicalTrials.gov (NCT04119011)

\section{INTRODUCTION}

Primary dysmenorrhoea is a common ailment of women of reproductive age, which is often underappreciated. Women experiencing dysmenorrhoea are often limited in functioning well at work and at school. It is a major cause of absenteeism and reduced quality of life as compared to women without this problem $(1,2)$. Primary dysmenorrhoea affects women with regular menstrual cycles in the absence of any organic disease such as endometriosis, uterine leiomyoma, adenomyosis or other uterine or ovarian pathologies.

Conventional treatment for primary dysmenorrhoea relies on the use of oral non-steroidal anti-inflammatory drugs (NSAIDs) and oral contraceptive pills to reduce inflammation and suppress ovulation. However, longterm treatment with NSAIDs can lead to peptic ulcer disease and impairment in kidney function while oral contraceptive pills lead to risks of thromboembolic disease $(3,4)$

To date, the exact pathogenesis of primary dysmenorrhoea is still unknown. Many studies attribute to the role of prostaglandins in mediating pain, uterine contraction and inflammation. Other inflammatory mediators such as leukotrienes and interleukins are also important in modulating this process (5). Leukotrienes released by lipoxygenase enzyme pathway exacerbate uterine contraction but their actions are not affected by NSAIDs. This could explain why NSAIDs may not be effective in some patients with primary dysmenorrhoea.

The relationship between gut dysbiosis, increased estrogen reabsorption and dysmenorrhoea has also been implicated in recent studies. Gut dysbiosis is thought to impair estrogen excretion thus exacerbate inflammation in primary dysmenorrhoea (6). Studies in Rhesus monkeys and humans affected with endometriosis have shown deficient aerobic Lactobacilli and higher gram negative organisms compared to healthy controls $(7,8)$.

Probiotic supplementation has been shown to colonize human intestine and confer many health benefits especially in immunomodulation and inflammatory conditions (9). In endometriosis, the use of Lactobacillus gasseri has been shown to suppress development of ectopic endometriotic lesions in a murine model and leads to improved visual analogue score and verbal rating score of dysmenorrhoea (10). However, research on the use of probiotics in women with primary dysmenorrhoea is still lacking. 
Hence, we designed this study to look at the potential benefits of probiotics in women with primary dysmenorrhoea. We hypothesized that an oral supplementation with probiotics for 3 months can restore gut dysbiosis thus improve the quality of life in women suffering from primary dysmenorrhoea.

\section{METHODS}

A double-blind randomized placebo-controlled trial was conducted in a university hospital in Malaysia to determine the effects of oral probiotic supplementation for 3 months in women with primary dysmenorrhea on quality of life. This study was approved by the institutional ethics committee (FF-2018-204) and registered under ClinicalTrials.gov (NCT04119011). We followed CONSORT guidelines to produce this report and analysis was done based on intention-to-treat.

\section{Participants}

Women who presented to the University Kebangsaan Malaysia Medical Center (UKMMC) between October 2019 and March 2020 who had primary dysmenorrhea were offered to participate in the study. All participants were provided with written informed consent. Eligible women were pre-menopausal women aged between 18-45 years old with regular menstrual cycle, having primary dysmenorrhea (pain on the first 2 days with no previously known gynaecological pathology), and willing to consume oral sachets twice daily for 3 months. We excluded women who were on intrauterine copper device, had recent hormonal treatment or contraceptives within last 3 months, had food allergy or lactose intolerance, had suspected or confirmed tumour or malignancy, frequent user of laxative or anti-diarrhoeal drugs, or who were receiving treatment for allergic diseases. Upon recruitment, data regarding demographics and menstrual history were collected.

\section{Intervention}

The treatment group received oral probiotic sachets containing 5 billion CFUs each of Lactobacillus acidophilus, Lactobacillus casei, Lactobacillus lactis, Bifidobacterium bifidum, Bifidobacterium longum, and Bifidobacterium infantis, while the placebo group received identical sachets containing excipients alone (BCrobes, Subang Jaya, Malaysia). Participants were instructed to take one sachet twice daily continuously for 3 months. Enough supply was given for each participant and compliance was self-reported during monthly assessment. All participants also received oral Mefenamic acids 250mg (Ponstan) for use when needed during study period.

\section{Outcomes}

The primary outcome was the improvement in quality of life scores on second day of menses before and after treatment using pain score, severity score, quality of life score and frequency of NSAIDs use as indicators. We measured the pain score using Visual Analog Scale (VAS), severity score using Verbal Rating Scale (VRS) and Quality of Life (QoL) score using Short Form 12 Item version 2 (SF12v2) questionnaire. This was a validated questionnaire used to assess the impact of pain on physical and mental health based on many researches on quality of life. Permission for use in this study was sought from the primary author and was granted.

\section{Study plan}

The research clinicians identified eligible participants from patients in clinics and wards in UKMMC. Women who agreed and met the inclusion criteria were counseled regarding the study and informed consent obtained. Participants were recruited on second day of menses and asked to fill up the visual analogue scale (VAS), verbal rating scale (VRS) and the SF12v2 questionnaire. All participants were given a pain diary to document the menstrual flow, pain intensity and frequency of oral NSAID use throughout 3-month treatment period. Participants were randomized upon recruitment and treatment boxes were dispensed accordingly. Subsequently participants were contacted once a month to assess side effects and compliance. At the end of the third month treatment period, patient was called back for assessment on second day of menses whereby the visual analogue scale, the verbal rating scale and the SF12v2 questionnaire were repeated. The pain diary was also collected. 


\section{Sample size}

A sample size of 72 was calculated to estimate the proportion of recruited women who would complete the study. Based on a study done by Faranak SD, this sample size would allow us to detect with at least $80 \%$ power a difference in the mean score with $95 \%$ confidence, taken into consideration a dropout rate of $20 \%$ (11).

\section{Randomization}

Study participants were randomly allocated to placebo or probiotic group using computerized randomization on 1:1 ratio in alternating sequence.

\section{Blinding and allocation concealment}

The probiotic and placebo sachets were prepared by the probiotic manufacturing company in identical packaging. Each sachet was individually labeled as A or B which contain either probiotics or placebo. The sachets were then packaged into identical tamper-proof boxes with details regarding expiry date, storage instructions and instructions for use. Only the manufacturer's company was aware of the content of the sachets. Both researchers and participants were blinded to the study grouping.

\section{Statistical Analysis}

Descriptive analysis was used to report baseline characteristics of study participants by allocated group. Continuous variables were reported as mean and standard deviations whereas categorical or ordinal variables were reported as absolute and relative frequencies. For the outcome measurement, we calculated median scores for ordinal variables and mean scores for continuous variables and compared using non-parametric Mann-Whitney U test. P-value of less than 0.05 was considered significant.

All analysis was performed using Statistical Package for Social Sciences (SPSS) version 23.

\section{Patient or public involvement}

There was no involvement from patient or public in the design of the study. There was no core outcome set applicable for this trial. All participants were informed regarding their group allocation and study findings at the end of the trial. We are planning to disseminate information through newsletter and patient information leaflets following primary publication of these results through our patient network.

\section{Funding}

This study received sponsorship from the company Biocrobes Sdn Bhd for three-months supply of placebo and probiotic sachets for all 72 patients.

\section{Result}

We identified 78 potential candidates between September 2019 to February 2020 who were eligible for the study. 6 women were excluded due to unwillingness to participate $(2 / 78)$ and not meeting the inclusion criteria (4/78). 72 women were randomized into placebo and probiotic group, each group consisted of 36 participants. At the end of the study, 5 participants were lost to follow up; $2(5.6 \%)$ from each group were uncontactable and $1(2.8 \%)$ from placebo group withdrew from the study (Figure 1). Compliance rates were reported to be $91 \%$ in the treatment group and $94 \%$ in the placebo group. The analysis was based on intention-to-treat and included $67(93 \%)$ of randomized women. There were some side effects such as diarrhoea, bloatedness and fever reported in the placebo group but no side effect reported from the probiotic group.

Characteristics of participants in the probiotic and placebo groups were similar as shown in Table 1. Majority was single with tertiary education level. There was similar representation from each ethnicity background in both treatment and control groups. Before treatment, the quality of life scores were comparable between the treatment and control group. Pain score was reported as moderate (6 to 7 out of 10), severity grade 2 out of 3 and physical and mental health scores in the range of 60 to 70 percentages (Table 1). 
After 3 months of treatment, both groups showed improvement but the placebo group showed better improvement in quality of life scores compared to the probiotic group. This was significant for the severity score (VRS) on second day of menses (mean rank $40.3 \mathrm{vs} 29.9, \mathrm{p}=0.02$ ). Other parameters were not significant. There was a non-statistically significant reduction of NSAIDs use in the probiotic group compared to the placebo group (mean rank 32.2 vs $36.8, \mathrm{p}=0.32$ ) (Table 2 ).

We performed a linear regression analysis on the use of NSAIDs on the quality of life scores and found that it was a significant predictor of VAS and VRS post treatment (co-efficient 0.143 , p-value $=0.01$ ). Hence a subgroup analysis based on the use of NSAIDs was performed (Table 3).

There was a higher proportion of NSAIDs use among participants in the placebo group (21/34, 61.7\%) compared to the probiotic group (18/33, 54.5\%). Among participants who did not take NSAIDs, there was a greater reduction of pain score (VAS) in the probiotic group compared to the placebo group (Figure 2). When NSAIDs was used, the placebo group showed greater improvement in the quality of life scores (Figure 2 and 3). This was significant for the severity score (VRS) (mean rank 24.5 vs 16.9, p-value 0.03). No other statistically significant difference found for pain score (VAS), physical health score and mental health score when adjusted for the use of NSAIDs (Table 4).

\section{Discussion}

The aim of this trial was to compare the effects of 3-months oral probiotics supplementation on quality of life in women with primary dysmenorrhea compared to placebo. Quality of life was measured using visual analog scale (VAS), verbal rating scale (VRS), physical and mental health scores derived from SF12v2 questionnaire, all taken on second day of menses before and after treatment.

\section{Main findings}

Oral probiotic supplementation twice daily in women with primary dysmenorrhea did not significantly improve the quality of life, however it could reduce the use of NSAIDs. This is the first trial that assessed the role of probiotics in primary dysmenorrhea. Previous researches were done on endometriosis and have suggested benefits of probiotics in reducing dysmenorrhea and modulating inflammatory response (10). Our study did not find improvement in the quality of life with the use of probiotics compared to placebo and NSAIDs. However, there was a trend towards reducing dependence on NSAIDs, which was clinically significant.

The most possible explanation to this finding was the use of NSAIDs masked the small improvement contributed by probiotics, and that the pain score, severity score, and the health scores were affected primarily by the use of NSAIDs. Furthermore, as primary dysmenorrhea was self-limiting after first two days of menstruation, the impact of probiotics on quality of life was not as evident.

\section{Strengths and weaknesses of the study}

'This study was a double-blind randomized controlled trial to compare the effects of oral probiotics compared to placebo in women with primary dysmenorrhoea. The double-blinding design reduced observer bias and the randomization process ensured similarity of baseline characteristics among participants in both groups. Three months supplementation was long enough to anticipate alteration in the gut microbiota and produce effect over three menstrual cycles as was usually prescribed for oral contraceptive pills or NSAIDs. The broad inclusion criteria enhanced external validity and low exclusion rate (6/78) and drop-out rate $(11 / 72)$ ensured internal validity. The use of intention-to-treat analysis further minimized the risk of bias and retained the randomization effect.

However, the study also has some limitations. The sample size was small hence was underpowered to detect a significant difference in the outcome. This was due to the confounding effect by use of NSAIDS, which masked the treatment effect. When this was adjusted for, the sample size and therefore the magnitude of effect was further reduced. To devise a study that compare the effect of probiotics alone versus NSAIDs would provide a clearer picture, but it was not ethically possible at the present time. Secondly, although the compliance rate was reported to be above $90 \%$ in each group, it was via self-reporting which was prone 
to reporter bias. We also did not measure the evolution of quality of life parameters per month and only measured at 2 points, which were before, and 3 months after treatment. Any benefit observed in the first two months could have been missed and lost at the end of treatment as a result of lack of compliance.

\section{Comparison with other studies}

Previous trials have demonstrated beneficial impact of oral probiotics in reducing dysmenorrhea and severity of symptoms in patients with endometriosis. In a randomized-controlled trial using lactobacillus gasseri in endometriosis patients, the menstrual pain was much reduced in the lactobacillus group compared to placebo (10). Another pilot randomized-controlled trial of 37 women with endometriosis also found significant improvement in pain score after use of oral lactobacillus for 8 weeks compared to placebo (12). However, the effect of probiotics was never tested in the population of women with primary dysmenorrhea. Many other trials on primary dysmenorrhea used alternative therapy such as herbal remedies, behavioural interventions, exercise, acupuncture, which showed improvement in menstrual pain but many of the studies were of unclear or low methodological quality (13-15).

\section{Implications for clinical practice and research}

With many discoveries being made daily relating to the benefits of probiotics in reproductive and general health conditions, our study was timely to assess the effect of probiotics in primary dysmenorrhea. This is a common ailment affecting women of reproductive age and constitutes a major health and economic burden in the loss of work and school productivity. Current strategies rely on the use of analgesia mainly non-steroidal anti-inflammatory drugs (NSAIDs), which offer symptomatic relief but do not target the root of the problem. Probiotics rich in lactobacillus promote a healthy gut environment and is proven beneficial in inflammatory diseases such as eczema, irritable bowel syndrome and endometriosis. The benefits may well be extrapolated to primary dysmenorrhea since it is also inflammatory in origin although the exact pathogenesis is still unclear. Although our study did not find significant improvement in the quality of life, it did show reduced use of NSAIDs, which suggested a 'less inflamed environment' in probiotic users. To further elucidate the benefits of probiotics in primary dysmenorrhea, a much larger sample size is required and to use a non-NSAIDs analgesia for pain relief such as paracetamol or tramadol.

\section{Conclusion}

Oral probiotics reduced NSAIDs use but did not affect quality of life in women with primary dysmenorrhea.

\section{Disclosure of interests}

All authors have completed the disclosure of interest form at www.icmje.org/coi_disclosure.pdf and declare no conflict of interest.

\section{Contribution to authorship}

The trial and study design was conceived by NAAG, RARA, AAZ, CKT and MAA. IAZ coordinated the trial with supervision from NAG and CKT. IAZ generated randomization sequence and analyzed the results with supervision from NS. NHAA and NFMM provided overall support to the conduct of the trial. IAZ wrote the first draft, which was further developed by NAAG. All authors contributed in the review and approval of the final manuscript.

\section{Details of ethics approval}

The Secretariat of Medical Research, University Kebangsaan Malaysia Medical Center (reference FF-2018204) approved the study on $5^{\text {th }}$ June 2018. All participants provided informed consent to take part in the trial.

\section{Funding}

This trial was funded using Fundamental Fund PPUKM and received sponsorship from Hexbio company for the supply of probiotic and placebo sachets in identical packaging. This report summarizes independent 
research conducted by the group of researchers. None of the funders or sponsors had influence in the design, conduct, data collection, analysis or interpretation of data, writing of the report or the decision to submit the paper for publication.

\section{Acknowledgements}

We thank the principal investigators and researchers, Dr Nur Aini Mohd Zain, and all women participated in this trial who contributed time and effort to make this trial a success. We thank Hexbio who sponsored the probiotic and placebo sachets and for their cooperation and customer support throughout the study.

\section{References}

1. Nur Azurah AG, Sanci L, Moore E, Grover S. The quality of life of adolescents with menstrual problems. J Pediatr Adolesc Gynecol [Internet]. 2013/01/23. 2013;26(2):102-8. Available from: https://www.ncbi.nlm.nih.gov/pubmed/23337310

2. Fernández-Martínez E, Onieva-Zafra MD, Parra-Fernández ML. The Impact of Dysmenorrhea on Quality of Life Among Spanish Female University Students. Int J Environ Res Public Health [Internet]. 2019;16(5):713. Available from: https://pubmed.ncbi.nlm.nih.gov/30818861

3. Suleyman H, Demircan B, Karagoz Y. Anti-inflammatory and side effects of cyclooxygenase inhibitors. Pharmacol Reports. 2007;

4. Sidney S, Cheetham TC, Connell FA, Ouellet-Hellstrom R, Graham DJ, Davis D, et al. Recent combined hormonal contraceptives (CHCs) and the risk of thromboembolism and other cardiovascular events in new users. Contraception. 2013;

5. Harel Z. Dysmenorrhea in adolescents and young adults: From pathophysiology to pharmacological treatments and management strategies. Expert Opinion on Pharmacotherapy. 2008.

6. López-Moreno A, Aguilera M. Probiotics dietary supplementation for modulating endocrine and fertility microbiota dysbiosis. Nutrients. 2020.

7. Bailey MT, Coe CL. Endometriosis is associated with an altered profile of intestinal microflora in female rhesus monkeys. Hum Reprod. 2002;

8. Leonardi M, Hicks C, El-Assaad F, El-Omar E, Condous G. Endometriosis and the microbiome: a systematic review. BJOG [Internet]. 2019/08/28. 2020;127(2):239-49. Available from: https://www.ncbi.nlm.nih.gov/pubmed/31454452

9. Van Baarlen P, Troost F, van der Meer C, Hooiveld G, Boekschoten M, Brummer RJM, et al. Human mucosal in vivo transcriptome responses to three lactobacilli indicate how probiotics may modulate human cellular pathways. Proc Natl Acad Sci U S A [Internet]. 2011 Mar 15 [cited 2019 Jun 2];108 Suppl 1(Suppl 1):4562-9. Available from: http://www.ncbi.nlm.nih.gov/pubmed/20823239

10. Itoh H, Uchida M, Sashihara T, Ji ZS, Li J, Tang Q, et al. Lactobacillus gasseri OLL2809 is effective especially on the menstrual pain and dysmenorrhea in endometriosis patients: Randomized, double-blind, placebo-controlled study. In: Cytotechnology. 2011.

11. Safdari-Dehcheshmehi F, Parvin N. The effect of mefenamic acid and melissa officinalis on primary dysmenorrhea: A randomized clinical trial study. Int J Pharmacogn Phytochem Res. 2016;

12. Khodaverdi S, Mohammadbeigi R, Khaledi M, Mesdaghinia L, Sharifzadeh F, Nasiripour S. Beneficial Effects of Oral Lactobacillus on Pain Severity in Women Suffering From Endometriosis: A Randomized Clinical Trial. Int J Fertil Steril. 2019;13.

13. Pellow J, Nienhuis C. Medicinal plants for primary dysmenorrhoea: A systematic review. Complement Ther Med [Internet]. 2018 Apr;37:13-26. Available from: https://linkinghub.elsevier.com/retrieve/pii/S0965229917307896 
14. Armour M, Ee CC, Naidoo D, Ayati Z, Chalmers KJ, Steel KA, et al. Exercise for dysmenorrhoea. Cochrane Database Syst Rev [Internet]. 2019 Sep 20 [cited 2020 Oct 11];(9). Available from: http://doi.wiley.com/10.1002/14651858.CD004142.pub4

15. Cho S-H, Hwang E-W. Acupuncture for primary dysmenorrhoea: a systematic review. BJOG An Int J Obstet Gynaecol [Internet]. 2010 Apr 1 [cited 2020 Oct 11];117(5):509-21. Available from: http://doi.wiley.com/10.1111/j.1471-0528.2010.02489.x

Table 1: Baseline characteristics and outcome according to treatment group

\begin{tabular}{|c|c|c|c|}
\hline $\begin{array}{l}\text { Characteristics/ } \\
\text { Outcome }\end{array}$ & Probiotic $(\mathrm{n}=36)$ & Placebo $(\mathrm{n}=36)$ & p-value \\
\hline \multicolumn{4}{|l|}{$\begin{array}{l}\text { Participant } \\
\text { characteristics }\end{array}$} \\
\hline $\begin{array}{l}\text { Age (years), median } \\
\text { (IQR) }\end{array}$ & $25(5)$ & $26(7)$ & 0.564 \\
\hline $\begin{array}{l}\text { Menarche (years), } \\
\text { median (IQR) }\end{array}$ & $12(2)$ & $12(1)$ & 0.730 \\
\hline $\begin{array}{l}\text { Menstrual cycle (days), } \\
\text { median (IQR) }\end{array}$ & $30(4)$ & $30(6)$ & 0.895 \\
\hline $\begin{array}{l}\text { Menstrual flow (days), } \\
\text { median (IQR) }\end{array}$ & $7(1)$ & $7(3)$ & 0.275 \\
\hline Education level, n (\%) & $35(97.2) 1(2.8)$ & $34(94.4) 2(5.6)$ & 1.000 \\
\hline $\begin{array}{l}\text { Marital status, n (\%) } \\
\text { Single Married }\end{array}$ & $29(80.6) 7(19.4)$ & $30(83.3) 6(16.7)$ & 1.000 \\
\hline Ethinicity, n (\%) Malay & $28(77.8) 5(13.9) 3(8.3)$ & $31(86.1) 4(11.1) 0(0.0)$ & 0.234 \\
\hline Chinese Indian Others & $0(0.0)$ & $1(2.8)$ & \\
\hline Occupation, n (\%) & $17(47.2) 14(38.9) 1(2.8)$ & $15(42.9) 18(51.4) 2(5.7)$ & 0.174 \\
\hline $\begin{array}{l}\text { Unemployed Employed } \\
\text { Self-employed Others } \\
\text { Quality of life before } \\
\text { treatment }\end{array}$ & $4(11.1)$ & $1(2.8)$ & \\
\hline $\begin{array}{l}\text { Visual Analog Scale, } \\
\text { median (IQR) }\end{array}$ & $7(2)$ & $6(2)$ & 0.646 \\
\hline $\begin{array}{l}\text { Verbal Rating Scale, } \\
\text { median (IQR) }\end{array}$ & $2(1)$ & $2(1)$ & 0.574 \\
\hline $\begin{array}{l}\text { Physical Health Score } \\
(\%), \text { mean (s.d) }\end{array}$ & $71.6(18.2)$ & $72.5(15.9)$ & 0.831 \\
\hline $\begin{array}{l}\text { Mental Health Score } \\
(\%), \text { mean (s.d) }\end{array}$ & $67.3(14.6)$ & $69.1(15.2)$ & 0.632 \\
\hline $\begin{array}{l}\text { Quality of life after } \\
\text { treatment }\end{array}$ & Probiotic $(n=34)$ & Placebo $(n=33)$ & p-value \\
\hline $\begin{array}{l}\text { Visual Analog Scale, } \\
\text { median (IQR) }\end{array}$ & $4(4)$ & $4(3)$ & 0.805 \\
\hline $\begin{array}{l}\text { Verbal Rating Scale, } \\
\text { median (IQR) }\end{array}$ & $1(1)$ & $1(1)$ & 0.019 \\
\hline $\begin{array}{l}\text { Physical health score } \\
(\%) \text {, mean (s.d) }\end{array}$ & $77.6(13.4)$ & $80.8(18.4)$ & 0.416 \\
\hline $\begin{array}{l}\text { Mental health score } \\
(\%), \text { mean (s.d) }\end{array}$ & $74.7(13.4)$ & $75.4(19.2)$ & 0.871 \\
\hline
\end{tabular}




\begin{tabular}{llll}
\hline $\begin{array}{l}\text { Characteristics/ } \\
\text { Outcome }\end{array}$ & Probiotic $(\mathrm{n}=36)$ & Placebo $(\mathrm{n}=36)$ & $\mathrm{p}$-value \\
\hline $\begin{array}{l}\text { Frequency of NSAIDs } \\
\text { use, median (IQR) }\end{array}$ & $1(4)$ & $2(6)$ & 0.266 \\
\hline
\end{tabular}

Table 2: Mann-Whitney-U test analysis of improvement of quality of life according to treatment group

\begin{tabular}{llll}
\hline Improvement of quality of life (post - pre) & Mean rank & Mean rank & p-value \\
\hline & Probiotic & Placebo & \\
Visual analog scale (VAS) & 35.8 & 34.2 & 0.73 \\
Verbal rating scale (VRS) & 29.9 & 40.3 & 0.02 \\
Physical health score (PHS) & 31.2 & 34.7 & 0.45 \\
Mental health score (MHS) & 32.7 & 33.3 & 0.90 \\
Frequency of NSAIDs use & 32.2 & 36.8 & 0.32 \\
\hline
\end{tabular}

Table 3: Quality of life scores post treatment based on NSAIDs use

\begin{tabular}{|c|c|c|c|c|c|c|}
\hline \multirow[t]{2}{*}{$\begin{array}{l}\text { Quality of } \\
\text { life } \\
\text { parameters }\end{array}$} & $\begin{array}{l}\text { Did not take } \\
\text { NSAIDs }\end{array}$ & $\begin{array}{l}\text { Did not take } \\
\text { NSAIDs }\end{array}$ & $\begin{array}{l}\text { Did not take } \\
\text { NSAIDs }\end{array}$ & $\begin{array}{l}\text { Took } \\
\text { NSAIDs }\end{array}$ & $\begin{array}{l}\text { Took } \\
\text { NSAIDs }\end{array}$ & $\begin{array}{l}\text { Took } \\
\text { NSAIDs }\end{array}$ \\
\hline & $\begin{array}{l}\text { Probiotic } \\
(n=15)\end{array}$ & $\begin{array}{l}\text { Placebo } \\
(n=13)\end{array}$ & p-value & $\begin{array}{l}\text { Probiotic (n } \\
=18)\end{array}$ & $\begin{array}{l}\text { Placebo }(\mathrm{n} \\
=21)\end{array}$ & p-value \\
\hline VAS post & $4(3)^{*}$ & $5(4)^{*}$ & 0.59 & $5(3)^{*}$ & $4(5)^{*}$ & 0.89 \\
\hline VRS post & $1(1)^{*}$ & $1(1)^{*}$ & 0.41 & $2(1)^{*}$ & $1(2)^{*}$ & 0.05 \\
\hline PHS post & $78.6(11.3)^{\wedge}$ & $81.2(15.4)^{\wedge}$ & 0.50 & $76.7(15.2)^{\wedge}$ & $80.6(20.4)^{\wedge}$ & 0.68 \\
\hline MHS post & $78.0(15.1)^{\wedge}$ & $74.3(19.1)^{\wedge}$ & 0.93 & $71.9(11.5)^{\wedge}$ & $76.0(19.7)^{\wedge}$ & 0.85 \\
\hline
\end{tabular}

*median (IQR), ^mean (std deviation)

Table 4: Mann-Whitney-U test analysis of improvement of quality of life based on NSAIDs use

\begin{tabular}{llll}
\hline Improvement of quality of life scores (pre-post) & Mean rank & Mean rank & Mean rank \\
\hline & Did not use NSAIDs & Did not use NSAIDs & Did not use \\
& Probiotic & Placebo & -value \\
VAS & 15.3 & 13.6 & 0.824 \\
VRS & 13.3 & 15.9 & 0.427 \\
PHS & 13.5 & 15.7 & 0.366 \\
MHS & 14.6 & 14.4 & 0.788 \\
\hline
\end{tabular}

\section{Hosted file}

Figure 1 consort.pdf available at https://authorea.com/users/367751/articles/487061the-effect-of-probiotics-on-quality-of-life-in-women-with-primary-dysmenorrhoea-arandomized-double-blind-placebo-controlled-trial 


\section{Hosted file}

Figure 2 comparison.pdf available at https://authorea.com/users/367751/articles/487061the-effect-of-probiotics-on-quality-of-life-in-women-with-primary-dysmenorrhoea-arandomized-double-blind-placebo-controlled-trial

\section{Hosted file}

Figure 3 qol.pdf available at https://authorea.com/users/367751/articles/487061-the-effectof-probiotics-on-quality-of-life-in-women-with-primary-dysmenorrhoea-a-randomizeddouble-blind-placebo-controlled-trial 